\title{
Microstructural characterization of binary microstructure pattern in selective laser-melted Ti-6AI-4V
}

\author{
M. Neikter ${ }^{1}$ (D) A. Huang ${ }^{2,3} \cdot X . W^{2}$ \\ Received: 19 March 2019 / Accepted: 11 June 2019 /Published online: 2 July 2019 \\ (C) The Author(s) 2019
}

\begin{abstract}
Selective laser melting (SLM) is an additive manufacturing process that offers efficient manufacturing of complex parts with good mechanical properties. For SLM, process parameters and post-processing are of importance as they affect the microstructure and consequently the mechanical properties. A feature in the microstructure, which is formed in SLM due to the fast cooling rate, is a binary microstructure pattern (BMP). The BMP is found in the horizontal plane and is formed with various laser scan angles between adjacent layers. The easiest distinguishable strategy is $90^{\circ}$, which renders a shape similar to a chessboard. In this work, the BMP phenomenon was investigated in detail and a microstructural characterization was performed on the fine microstructure zone (FMZ) that separates the coarse microstructure zones (CMZ), by using light optical and scanning electron microscopes (SEM) that were equipped with electron backscattered (EBSD) and energy dispersive $\mathrm{x}$-ray spectroscopy (EDS) detectors. Moreover, the effect of the process parameter hatch distance on the BMP was investigated and the overlapping between neighboring scan tracks in SLM was found to influence the size of the BMP, while the thickness of the FMZ remained constant. Different post-SLM heat treatments were performed and it was shown that the BMP retained unless the heat treatment temperature reached above the $\beta$ transus temperature. EBSD and $\beta$ grain reconstruction were performed as well to reveal the columnar $\beta$ grain orientations. The result showed that each CMZ and FMZ originates from a respective parent $\beta$ grains.
\end{abstract}

Keywords Selective laser melting (SLM) $\cdot$ Microstructure $\cdot$ Chessboard $\cdot$ Ti-6Al-4V $\cdot$ Prior beta

\section{Introduction}

In order to achieve desired mechanical properties of metallic products by additive manufacturing (AM), it is important to control the process parameters that affect heat input to the material and the cooling rate, which in turn affect the microstructure. In AM, there are a large number of tunable process parameters [1-5] and relatively complex thermal history [6] that results in microstructural changes. As one of many AM processes [6, 7], the selective laser melting (SLM) process uses a focused laser beam to melt consecutive layers of metal

M. Neikter

magnus.neikter@1tu.se

Luleå University of Technology, 97187 Luleå, Sweden

2 Monash Centre for Additive Manufacturing, Monash University, Melbourne 3800, Australia

3 School of Materials Science and Engineering, University of Shanghai for Science and Technology, Shanghai 200093, China powder. It is a widely used powder bed fusion process and is advantageous in making small batches of geometrically complex parts with a high level of customization, shortened lead times, and reduced material cost [8]. The geometrical freedom of design for AM allows for reduced use of materials, which makes relatively expensive materials such as titanium alloys particularly interesting for AM.

The SLM process has a faster cooling rate than the electron beam melting (EBM) process due to the argon atmosphere in SLM having higher thermal conductivity than a vacuum in EBM [9] and that the build platform is kept at a lower temperature $\sim 100{ }^{\circ} \mathrm{C}$ [3]. The fast cooling rate results in the formation of predominant martensitic $\alpha^{\prime}$ microstructure [3, $10,11]$, where prior $\beta$ grains grow epitaxially throughout the deposition layers [3, 8, 12-14]. It renders a material with high strength and low ductility, residual stresses [15], solidification texture [16], and twins [17], which is opposite to the EBM-built material that has a coarser basketweave [4] microstructure and little residual stresses [18]. Scanning strategies are important for the residual stresses in selective laser melting. For example, Mugwagwa et al. [19] have shown that the 
chessboard scanning strategy resulted in $40 \%$ less residual stresses compared to the default island scanning strategy. One the other hand, Ali et al. [20] reported that the $90^{\circ}$ alternating strategy to result in the lowest amount of residual stresses of five investigated strategies. Apart from residual stresses, scanning strategies have also been shown to influence the relative density $[21,22]$.

The $\alpha^{\prime}$ needles can be categorized into four subgroups [12, 23]: primary, secondary, tertiary, and quaternary. The width of the acicular $\alpha^{\prime}$ needles ranges from microns in the case of primary $\alpha^{\prime}$ down to nanometers for quaternary $\alpha^{\prime}$. It is believed that the primary and secondary martensitic needles nucleate at an early stage of the $\beta$ to $\alpha^{\prime}$ phase transformation, whereas the tertiary and quaternary needles at a later stage, thus their nucleation is hindered by the existing primary and secondary $\alpha^{\prime}$ needles [12]. The mechanical properties are largely influenced by the size of the martensitic acicular $\alpha^{\prime}$ needles and the orientation of the prior $\beta$ grains, which is partly responsible for the mechanical anisotropy observed in SLM built titanium alloys $[10,24,25]$. The prevalent martensitic $\alpha^{\prime}$ microstructure of SLM Ti-6Al-4V often results in high strength and low ductility. To overcome the decreased ductility, post-SLM heat treatment, with the sacrifice of strength [24], can be performed. Xu et al. [8] performed post-SLM heat treatments on SLM built Ti-6Al$4 \mathrm{~V}$ to understand at which temperatures an ultrafine $\alpha+\beta$ could be obtained with good mechanical properties, with the result being in the range of $400{ }^{\circ} \mathrm{C}$ for $2 \mathrm{~h}$ [8]. Cao et al. [17] investigated the influence of different post-SLM heat treatments on martensite decomposition, this was performed by measuring the $\beta$ phase fraction and subsequent transmission electron microscope (TEM) analysis of retained martensite. It was shown that heat treatments at 700 and $800{ }^{\circ} \mathrm{C}$ for $2 \mathrm{~h}$ are insufficient to fully decompose the martensite. However, after a heat treatment at $800{ }^{\circ} \mathrm{C}$ for $6 \mathrm{~h}$, a complete martensite decomposition was achieved, which resulted in increased ductility. It is also known that sub $\beta$ transus $\left(995{ }^{\circ} \mathrm{C}\right.$ for Ti-6Al-4V [26]) heat treatments do not alter the size and shape of the prior $\beta$ grains, while super $\beta$ transus heat treatments cause significant $\beta$ grain growth and transformation of columnar $\beta$ grains to equiaxed $\beta$ grains [1].

Apart from post-SLM heat treatments, process parameters are also important for the final mechanical properties, affecting, e.g., defects [27] and microstructure [4]. For example, Pal et al. [23] vary the process parameter energy density by adjusting the scanning speed and measured the impact on volume, shape, and number of pores. They found a difference of $2.45 \%$ between the sample with the highest and lowest relative density. Xu et al. [8] demonstrated the possibility of achieving an in situ martensite decomposition in the SLM process through the control of process parameters, i.e., layer thickness and laser beam focal offset distance. By optimizing the energy density, Xu et al. [8] obtained an ultrafine $\alpha+\beta$ microstructure with slightly lower strength $(>1100 \mathrm{MPa})$ but much higher ductility (11.4\% elongation to failure) than martensite.
In the SLM process, there is a phenomenon called the binary microstructure pattern (BMP), since the pattern consists of two different microstructures. Fine microstructure zones (FMZ) are formed around a coarse microstructure zone (CMZ), which can potentially affect the mechanical properties. The size of the BMP has been shown to correlate with the hatch spacing $[3,10,12]$, where an increase in hatch spacing renders an increased size of the BMP. Thijs et al. [28] investigated different scanning strategies for SLM built Ti-6Al-4V and found the morphology of the BMP varies. The BMP is not unique only for titanium but is also present in other SLM built materials, e.g., 316 stainless steel [29] and nickel-based superalloys [30].

This paper characterizes the microstructural difference between FMZ and CMZ by using scanning electron microscope (SEM), light optical microscope (LOM), and electron backscattered diffraction (EBSD). In addition to the EBSD, prior $\beta$ grain reconstruction is utilized to show the correlation of $\beta$ grain morphology with BMP. Furthermore, the effect of the overlapping between neighboring hatches on the BMP is investigated.

\section{Material and method}

The powder used in this study was gas atomized Ti-6Al-4V powder provided by Falcon Tech Co. A Concept Laser X-Line 1000 was used to fabricate the samples, while the process chamber was flooded with argon gas and the substrate heated and held at $100{ }^{\circ} \mathrm{C}$. To investigate the influence of the hatch distance on the size of CMZ and FMZ, the overlapping between neighboring scan tracks was defined as shown in Eq. 1. Four cuboid samples (Sample A-D) with dimensions $8 \mathrm{~mm} \times$ $8 \mathrm{~mm} \times 40 \mathrm{~mm}$ were manufactured using various hatch distances, thus resulting in different amounts of overlapping. The molten track width (MTW) in Eq. 1 was determined experimentally. A cylindrical thin wall sample with a single pass each layer was fabricated using the laser power, scan speed, and layer thickness as defined in Table 1 . The inner and outer diameters of the cylindrical thin wall sample were then measured using a Crysta-Apex S coordinate measuring machine. The MTW was taken as half the difference between the inner and outer diameters and was measured as $0.360 \mathrm{~mm}$. The overlapping can thus be defined as:

Overlapping $=1-\frac{\text { hatch distance }}{\text { MTW }}$

The energy densities were calculated based on the process parameters according to [28], where $P$ is the laser power, $v$ the scan speed, $h$ the hatch distance, and $t$ the layer thickness: 
Table 1 Process parameters for the four investigated materials. L. = layer and E. = energy

\begin{tabular}{llllllll}
\hline Set & Hatch distance & Hatching & Overlapping & Power & Speed & L. thickness & E. density \\
\hline A & $0.108 \mathrm{~mm}$ & $90^{0}$ & $70 \%$ & $350 \mathrm{~W}$ & $770 \mathrm{~mm} / \mathrm{s}$ & $50 \mu \mathrm{m}$ & $84 \mathrm{~J} / \mathrm{mm}^{3}$ \\
B & $0.144 \mathrm{~mm}$ & $90^{0}$ & $60 \%$ & $350 \mathrm{~W}$ & $770 \mathrm{~mm} / \mathrm{s}$ & $50 \mu \mathrm{m}$ & $63 \mathrm{~J} / \mathrm{mm}^{3}$ \\
C & $0.180 \mathrm{~mm}$ & $90^{\circ}$ & $50 \%$ & $350 \mathrm{~W}$ & $770 \mathrm{~mm} / \mathrm{s}$ & $50 \mu \mathrm{m}$ & $51 \mathrm{~J} / \mathrm{mm}^{3}$ \\
D & $0.216 \mathrm{~mm}$ & $90^{\circ}$ & $40 \%$ & $350 \mathrm{~W}$ & $770 \mathrm{~mm} / \mathrm{s}$ & $50 \mu \mathrm{m}$ & $42 \mathrm{~J} / \mathrm{mm}^{3}$ \\
\hline
\end{tabular}

$E=\frac{P}{v^{*} h^{*} t}$

The energy density values for the different material are shown in Table 1. In addition, the target laser spot size was $0.1 \mathrm{~mm}$. For the microstructural characterization, the samples were baked into a conductive phenolic cure and then ground and polished according to standard metallographic preparation for titanium alloys. The samples were etched with Kroll's reagent according to ASTM Standard E 407 (192) to reveal the microstructure. The LOM used for the investigation was an Olympus GX51. Three types of SEMs were used for the work, an FEI Quanta 3D FEG, Jeol JSM7001F, and Jeol IT300LV. The former two were used for the $\alpha^{\prime}$ needle measurements, whereas the latter two were used for the EBSD characterization. The last SEM was also used for the EDS mapping. For the measurement of the width and length of the martensitic needles, high-resolution images were obtained by using SEM. The width and length of several hundred martensitic needles, on a considerable number of locations, were then measured using the software Image J. For EBSD, the detector NordlysMax ${ }^{2}$ was utilized and the parameters were set to an acceleration voltage of $20 \mathrm{kV}$ along with a step size ranging from 0.3 to $1.5 \mu \mathrm{m}$. The result was then later presented as inverse pole figure (IPF) maps.

Heat treatments were conducted at $700,800,900$, and $1020^{\circ} \mathrm{C}$ for $2 \mathrm{~h}$ each followed by air cooling to room temperature, to investigate the effect of heat treatments on the BMP. The samples used for the EBSD measurements had 50\% overlapping and were exposed to the heat treatment $700{ }^{\circ} \mathrm{C}$ for $2 \mathrm{~h}$ to relieve residual stresses. A single line experiment was conducted on a Ti-6Al-4V alloy substrate to study the shape of the melt pool and heat-affected zone (HAZ). The substrate was heated up to $100^{\circ} \mathrm{C}$ and a thin layer of powder was coated on the substrate. In order to approach the target value of the layer thickness of $50 \mu \mathrm{m}$, some fine adjustment was carried out. The adjustment started by coating a relatively thick layer of powder (a few hundred microns). Then the height of the substrate was raised gradually to a level at which the recoater is just making contact with the substrate surface without leaving behind any powder. Finally, the substrate was lowered by $50 \mu \mathrm{m}$ and a layer of powder was coated onto the substrate. The single line exposure was conducted at a laser power of $350 \mathrm{~W}$ and a scan speed of $770 \mathrm{~mm} / \mathrm{s}$. The chosen process parameters originate from previous research conducted at
Monash Centre for Additive Manufacturing [3], where parameter set $\mathrm{C}$ in Table 1 resulted in the best overall properties.

Figure 1a illustrates the relationship between the FMZ, CMZ, HAZ, and the melt zone (MZ, for one laser pass) for $50 \%$ overlapping. In, Fig. $1 \mathrm{~b}$, the $90^{\circ}$ hatching pattern that was used in the investigation is shown. The reason for using $90^{\circ}$ was because it was deemed to be easier distinguishable than other angles.

The EBSD data was used to reconstruct $\beta$ grains with a software called ARPGE [31]. ARPGE uses the crystal orientation from the daughter grains to recreate the parent grain by using Burger's orientation relationship, where twelve $\alpha$ ( $\alpha$ and $\alpha^{\prime}$ has the same crystal structure) variants can originate from one $\beta$ crystallographic orientation during the $\beta \rightarrow \alpha$ transformation. Humbert et al. showed [32] that for the inverse transformation, $\alpha \rightarrow \beta$, there can be six $\beta$ variants originating from one $\alpha$ crystallographic orientation. By knowing at least four $\alpha$ variants [33], it is then possible to calculate their parent $\beta$ crystallographic orientation. The standard settings used for ARPGE were as follows: a minimum number of daughter grains per parent grain: $5^{\circ}$, step for nucleation: $2^{\circ}$, step for growth: $2^{\circ}$, nucleation angle stop: $15^{\circ}$, growth angle stop: $20^{\circ}$. Energy dispersive $\mathrm{x}$-ray spectroscopy (EDS) mapping was performed to investigate if the segregation effect could be responsible for the microstructural variation between FMZ and CMZ. The EDS analysis was carried out on the elements that constitute Ti-6Al-4V, i.e., Ti, $\mathrm{Al}, \mathrm{V}, \mathrm{Fe}, \mathrm{O}$, and $\mathrm{C}$.

\section{Results}

\subsection{Microstructure and statistics of $\alpha^{\prime}$ geometry in $\mathrm{CMZ}$ and $\mathrm{FMZ}$}

The microstructure of the as-built Ti-6Al-4V showed a dominant presence of martensitic $\alpha^{\prime}$ needles due to the fast cooling rate, where columnar prior $\beta$ grains were found to span across a few deposition layers and were aligned parallel to the build direction, as shown in Fig. 2a. Figure $2 b$ shows the boundary between the FMZ and CMZ, where the coarser microstructure of the CMZ is evident. The length and width of the $\alpha^{\prime}$ needles were measured within the FMZ and CMZ, and the results of these measurements are shown in Fig. 3 and Table 2. Figure 3a shows the relationship between the aspect ratio and length of 


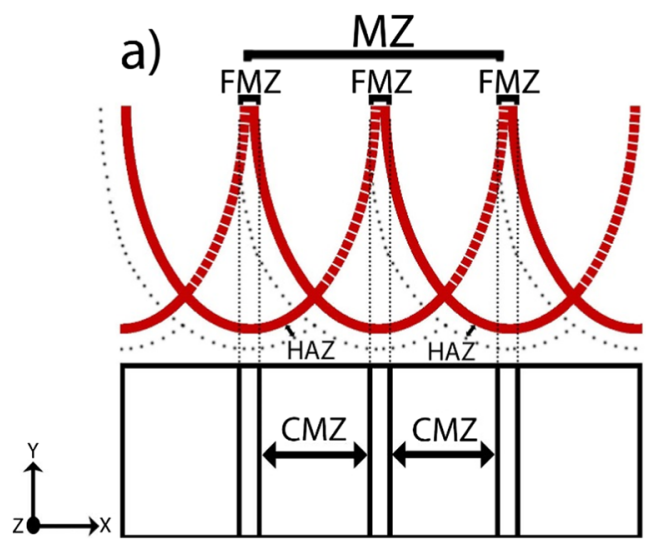

Fig. 1 a An illustration showing the relationship of the fine microstructure zone (FMZ), coarse microstructure zone (CMZ), and melt zone (MZ) with $50 \%$ overlapping of the laser beam (red halfellipse). The $\mathrm{MZ}$ is equal to the hatch spacing times two. $\mathrm{Z}$ is in the build direction, $\mathrm{Y}$ the scan direction, and $\mathrm{X}$ the transverse direction.

the $\alpha^{\prime}$ needles, whereas Fig. $3 \mathrm{~b}$ shows the distribution of the $\alpha^{\prime}$ needles in regard to their width. The CMZ showed a wider spread in the distribution of the $\alpha^{\prime}$ length (Fig. 3a) and width (Fig. 3b). The observation that CMZ had a coarser microstructure is further validated by the higher median and average of the length and width of the martensitic $\alpha^{\prime}$ needles found in CMZ (Table 2). Additionally, the $\alpha^{\prime}$ needles in CMZ have a larger maximum aspect ratio compared to those in FMZ.

Figure $3 \mathrm{c}$ shows the microstructure of SLM processed Ti64 sample in the vertical plane parallel to the build direction. The columnar prior $\beta$ grains grow epitaxially along the build direction (Z). The FMZs separating prior $\beta$ grains appear as light contrast as indicated by the white arrows.

\subsection{Effect of overlapping and HAZ measurement}

Four different overlappings were tested: 40, 50, 60, and 70\% (see Fig. 4). The effect of the overlappings was measured on both the width of the FMZ and CMZ. The results of these measurements are shown in Fig. 5a. The width of the FMZ b) $90^{\circ}$ Hatching

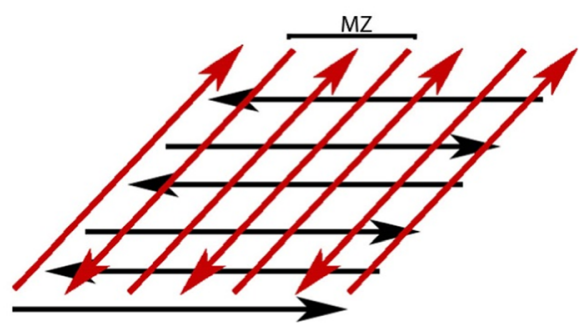

The melt direction is from right to left, i.e., striped red lines indicate melt zones that are re-melted. The hatching, as shown in $\mathbf{b}$, was performed with a $90^{\circ}$ change between the adjacent layers, where red and black correspond to two separate layers

for the four cases ranged from $15.8 \pm 2.6$ to $18.1 \pm 1.8 \mu \mathrm{m}$. The average widths of the CMZ for the 40,50, 60, and 70\% overlapping were $212 \pm 8 \mu \mathrm{m}, 166 \pm 12,139 \pm 13$, and $106 \pm$ 7 , respectively. It is noteworthy that FMZ was absent between neighboring $\mathrm{CMZ}$ in some cases. The $\alpha^{\prime}$ needles for neighboring CMZ without FMZ in-between have different crystallographic orientations, thus creating a boundary, even though there is no FMZ in-between. Some CMZ were clear, i.e., areas of dark contrast in Fig. 4, while others remained undefined even after prolonged etching. In Fig. 5b, the white dotted lines and the double pointing arrows indicate the HAZ, where a microstructural difference indicated the HAZ and MZ interface. The width of HAZ was measured to be $25 \pm 7 \mu \mathrm{m}$.

\subsection{Beta grain reconstruction}

As Fig. 4 does not show the FMZ and CMZ clearly in some cases, EBSD was used to further study the grain orientations (see the IPF map in Fig. 6a). The $\beta$ grains were then reconstructed (see Fig. 6b) from Fig. 6a. Different colors represent
Fig. 2 a Overview of the macrostructure in SLM built Ti$6 \mathrm{Al}-4 \mathrm{~V}$, showing the square BMP at the top and the columnar prior $\beta$ grains on the sides. The black arrow points at the build direction (Z), i.e., perpendicular to the layers. b An SEM image showing the border of the fine microstructure zone (FMZ) and the coarse microstructure zone (CMZ). The CMZ has both longer and wider martensitic needles than FMZ. The sample was fabricated by $50 \%$ overlapping
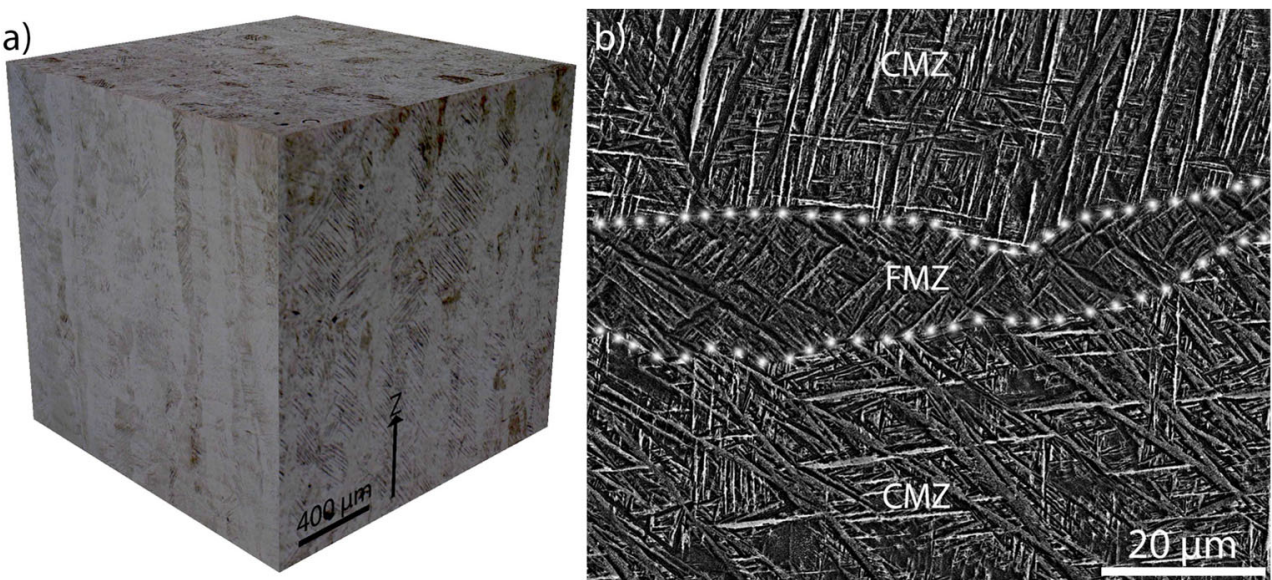

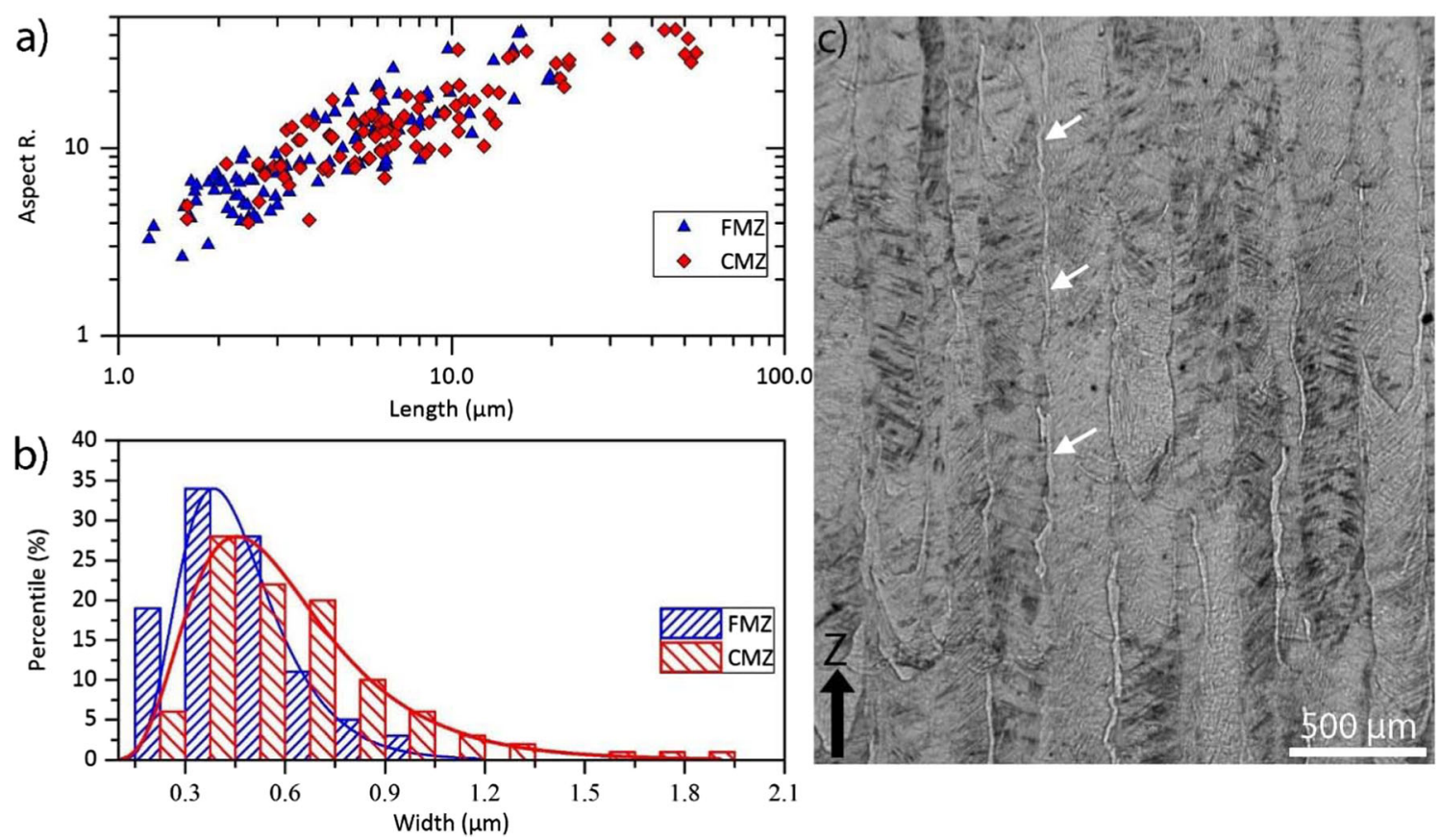

Fig. 3 A graph showing the aspect ratio plotted against the length of the $\alpha^{\prime}$ needles is shown in a for both the FMZ and CMZ (both axes are in logarithmic format). The distribution of the $\alpha^{\prime}$ needles in regard to their width for FMZ and CMZ is shown in $\mathbf{b}$. In $\mathbf{c}$, a side view of the

different crystallographic orientations. It is clear from Fig. 6 that each CMZ has a distinct $\beta$ crystallographic orientation from its neighboring $\beta$ grains. From this result and the columnar shape of the prior $\beta$ grains in Fig. 3c, the $\beta$ grains could be regarded as rectangular cuboid shaped. It is noteworthy that the EBSD result had a relatively high amount of non-indexed pixels $(\sim 30 \%)$, which could be related to the fine martensitic microstructure, residual stresses, and lattice distortion. Consequently, not all reconstructed $\beta$ grains are perfectly square shaped in Fig. 6 b.

For the lower magnification EBSD measurement, the step size was too coarse for the $\beta$ reconstruction to detect any FMZ. However, for the higher magnification, EBSD measurement shown in Fig. 7 where smaller step $(0.3 \mu \mathrm{m})$ size was used the FMZ was also determined to originate from a distinct $\beta$ grain. It is moreover evident that the FMZs between CMZ can be discontinuous at some locations.

Figure 8 shows an IPF map on the vertical plane and its corresponding reconstructed $\beta$ grains. The $\beta$ grains have a microstructure is shown where the black arrow indicates the build direction and the white arrows the FMZ. The sample was fabricated by $50 \%$ overlapping with the cross section being angled with $45^{\circ}$ in regard to the hatch lines

columnar shape that grows through several layers. The width of the $\beta$ grains varies in size and in some cases the large $\beta$ grains are surrounded by smaller $\beta$ grains that have the same width as the FMZ.

\subsection{Effect of heat treatments on BMP}

Figure 9 shows the microstructural evolution on the horizontal plane of SLM built Ti-64 after isothermal heat treatment at temperatures of $700,800,900$, and $1200{ }^{\circ} \mathrm{C}$. At temperatures below the $\beta$ transus temperature $\left(995^{\circ} \mathrm{C}\right)$, the BMP is retained after heat treatments. For $700{ }^{\circ} \mathrm{C}$ heat treatment, there was no obvious change to the microstructure compared to the as-built condition. For heat treatments at higher temperatures of 800 and $900{ }^{\circ} \mathrm{C}$, the microstructure became coarser, but the BMP was still distinguishable. The BMP did, however, disappear after heat treatment at $1020{ }^{\circ} \mathrm{C}$ for $2 \mathrm{~h}$ and a coarser basketweave microstructure emerged.
Table 2 The median, average, and standard deviation for the length, i.e., major axis, width, i.e., minor axis, and aspect ratio (A.R.) for the fine microstructure zone (FMZ) and coarse microstructure zone (CMZ)

\begin{tabular}{|c|c|c|c|c|c|c|}
\hline & \multicolumn{3}{|l|}{ FMZ } & \multicolumn{3}{|l|}{$\mathrm{CMZ}$} \\
\hline & Length $(\mu \mathrm{m})$ & Width $(\mu \mathrm{m})$ & A.R. & Length $(\mu \mathrm{m})$ & Width $(\mu \mathrm{m})$ & A.R. \\
\hline Median & 3.9 & 0.4 & 8.4 & 6.3 & 0.5 & 12.7 \\
\hline Average & 5.3 & 0.5 & 11.4 & 11.1 & 0.6 & 15.9 \\
\hline St. dev. & 4.3 & 0.2 & 8.0 & 12.3 & 0.3 & 9.8 \\
\hline
\end{tabular}


Fig. 4 LOM micrographs of $70 \%$ (a), $60 \%$ (b), $50 \%$ (c), and $40 \%$ (d) overlapping. With a decreasing overlapping, the size of the CMZ increased. The black dashed line indicates roughly the BMP for the four different overlapping amounts

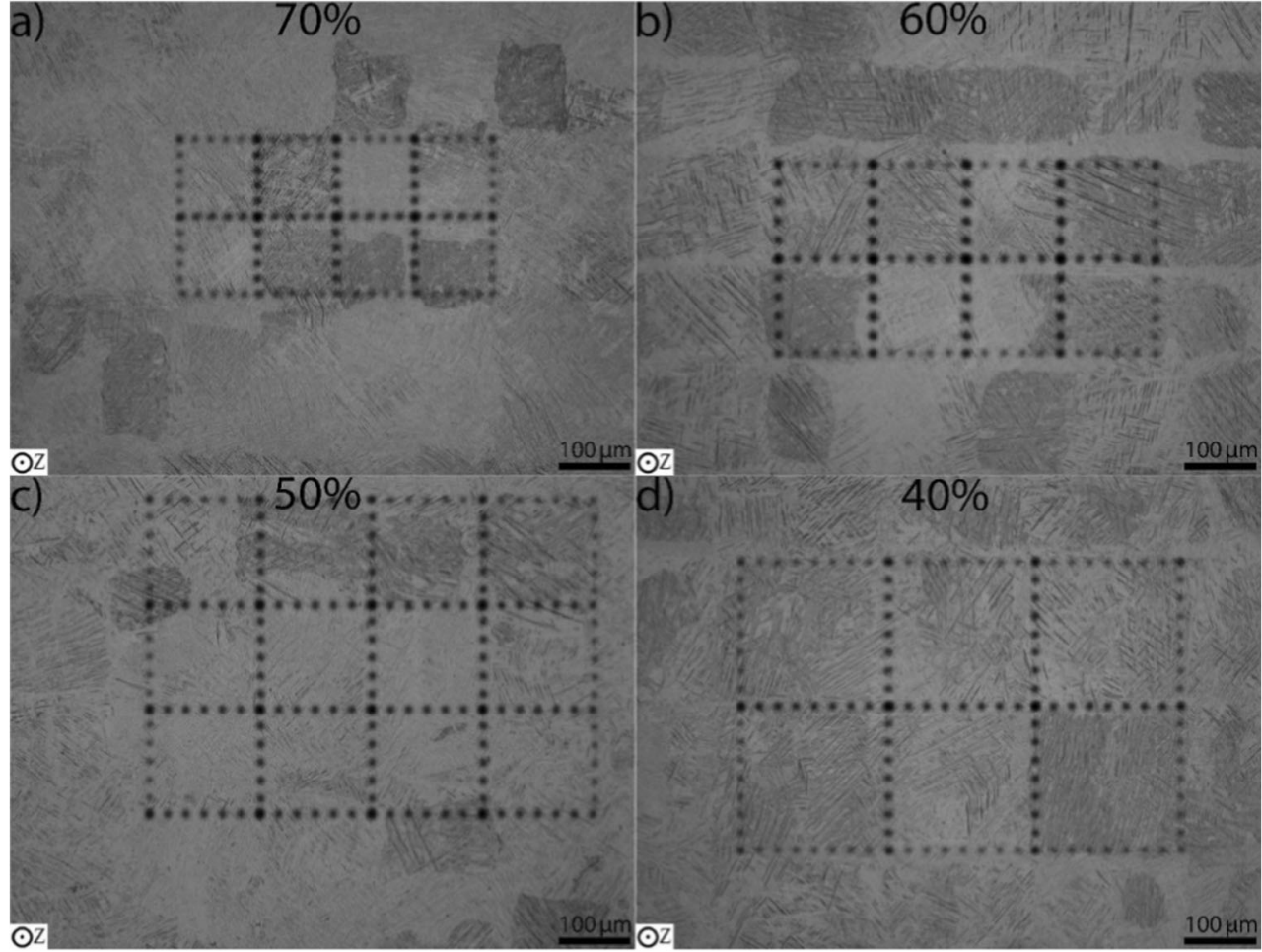

\subsection{EDS mapping}

EDS mapping was performed in the horizontal plane to investigate the element distribution. Ti-6Al-4V constitutes of $\mathrm{Ti}, \mathrm{Al}$, and $\mathrm{V}$ and small amounts of $\mathrm{Fe}, \mathrm{O}$, and $\mathrm{C}$ and all of these element concentrations were measured to clarify if there were any segregational effects that could explain the formation of the binary microstructure. However, the distribution maps of the elements were homogenous, as shown in Fig. 10, and the alloy composition was according to Ti-6Al-4V standard (Ti $~ 90 \mathrm{wt} \%, \mathrm{Al} \sim$
$6 \mathrm{wt} \%, \mathrm{~V} \sim 4 \mathrm{wt} \%, \mathrm{Fe}, \mathrm{O}$, and $\mathrm{C}<1$. This indicates that no segregation effects were responsible for the formation of the BMP.

\subsection{Texture from EBSD measurement}

In Fig. 11, pole figures based upon the EBSD measurement presented in Fig. 8 are shown. Textures for the three hexagonal close-packed (HCP) slip planes are shown and the strongest texture was present in the (0002) plane, for the X-Y plane. In this direction (see red points in the (0002) plane), the
Fig. 5 a The measurements of the width of the FMZs and the CMZs are shown for the different overlapping amounts $40 \%, 50 \%$, $60 \%$, and $70 \%$. b Back-scattered electron image of the cross section of single track sample fabricated on a Ti-6Al-4V substrate showing both the width and depth of the melt. The HAZ is marked with the white double pointing and the dotted line




Fig. 6 Lower magnification image of material where $50 \%$ overlapping was used. The material received a $700{ }^{\circ} \mathrm{C}$ heat treatment for $2 \mathrm{~h}$ to relieve residual stresses. a An IPF map and $\mathbf{b}$ its corresponding $\beta$ grain reconstruction. Different colors signify different crystal orientations and each CMZ in $\mathbf{b}$ correspond to one distinct $\beta$ grain. $\mathrm{Z}$ indicates the build direction

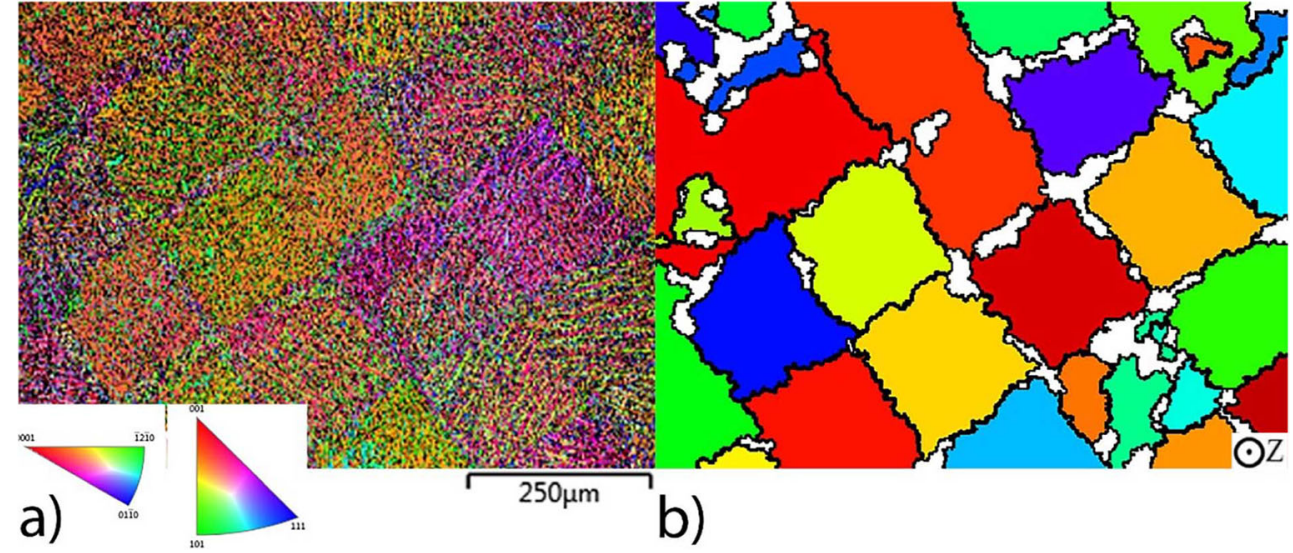

multiples of random distribution (MUD) reached 11.72. For the two other investigated slip planes, no such strong texture was present, reaching maximum MUD of $\sim 6$.

\section{Discussion}

Figure 1a schematically illustrates how the FMZ is correlated with laser melting under the condition $50 \%$ overlapping. For $50 \%$ overlapping, the hatch distance is set at half of the measured track width (MTZ), and Fig. 1b illustrates the rotation of the laser scan direction by $90^{\circ}$. If this pattern changes, the pattern of the FMZ also changes [28]. The width of the FMZ also sets an upper limit on the length of martensitic $\alpha^{\prime}$ needles. It is noteworthy that the maximum length of the major axis for the $\alpha^{\prime}$ needles is in the same order of magnitude as the width of the FMZ, i.e., roughly $20 \mu \mathrm{m}$. The hierarchical martensitic (primary to quaternary $\alpha^{\prime}$ needles) structure that was observed by Pal et al. [23] and Yang et al. [12] was also observed in this work, for both the FMZ and CMZ.

Heat treatments were performed to investigate the temperature at which the BMP would disappear. The BMP remained after heat treatment at $900{ }^{\circ} \mathrm{C}$ for $2 \mathrm{~h}$ and disappeared after heat treatment above the $\beta$ transus temperature $\left(1020^{\circ} \mathrm{C}\right)$. The reason for this is explained by the reconstructed $\beta$ grains from the EBSD data. It was shown that the $\alpha^{\prime}$ crystals within the same $\mathrm{CMZ}$ originate from the same parent $\beta$ grain. Sub $\beta$ transus heat treatments are also reported to not alter either the shape or the size of the prior $\beta$ grains [26], therefore not affecting the BMP. The result showed that the size of the $\beta$ grains is in direct correlation with the hatch distance. In addition, Zhang et al. [34] measured the prior $\beta$ grain size with LOM and also noted the correlation of the $\beta$ grain size with the hatch distance. The columnar grains are known to grow through epitaxial growth and in the direction of the temperature gradient [35], and evidently the scan strategy acts as a barrier for growth to occur outside the hatch.

In this work, the layer thickness was set to $50 \mu \mathrm{m}$. Increasing this thickness would likely affect the BMP if the other process parameters were kept constant. As explained by Yadroitsev et al. [36], powder has a higher absorptivity and lower thermal conductivity than the substrate. Thus, increasing the layer thickness would result in a slower cooling rate. The BMP is dependent on the fast cooling rate of the SLM process; it is therefore possible that lowering the cooling rate by increasing the layer thickness would remove the BMP. However, remelting the substrate is crucial for stabilizing the SLM process [36], so there is a limit to how much the layer
Fig. 7 Higher magnification EBSD on the horizontal plane. The material received a $700{ }^{\circ} \mathrm{C}$ heat treatment for $2 \mathrm{~h}$ to relieve residual stresses. An IPF map is shown in $\mathbf{a}$ and is its corresponding $\beta$ grain reconstruction is shown in $\mathbf{b}$. Between the upper CMZs, FMZ is present, whereas no FMZ is present in between the lower CMZs. $\mathrm{Z}$ indicates the build direction




Fig. 8 EBSD map on the vertical plane. The material received a $700{ }^{\circ} \mathrm{C}$ heat treatment for $2 \mathrm{~h}$ to relieve residual stresses. Note that the cross section is angled with $45^{\circ}$ in relation to the hatch lines. In $\mathbf{a}$, the IPF map is shown and $\mathbf{b}$ shows the corresponding $\beta$ grain reconstruction. $\mathrm{Z}$ indicates the build direction. The reconstructed image shows that the $\beta$ grains are columnar and cover several layers

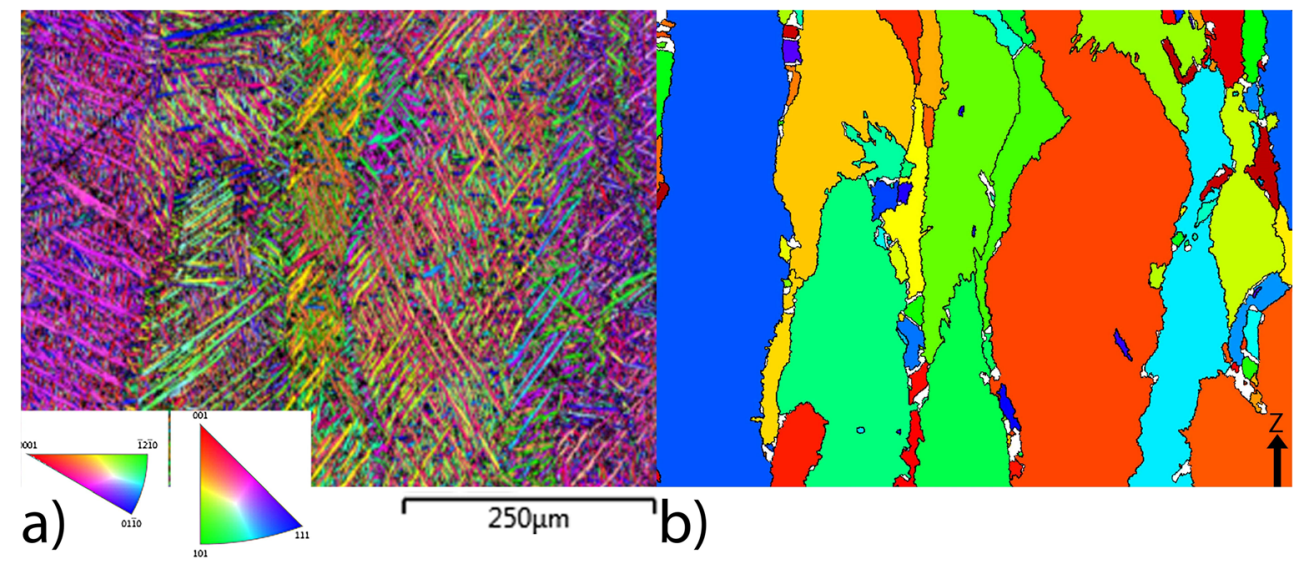

thickness can be increased before affecting the properties of the material severely. Moreover, increasing the layer thickness would also increase the melt volume, in turn affecting the $\mathrm{MZ}$ which from the presented results would alter the size of the CMZ. As explained by AlMangour et al. [21], layer thickness also affects the texture in the material. They found that partial remelting increases the texture, which translates into smaller layer thickness and/or hatch distance.

As illustrated in Fig. 1, the FMZ seems to coincide quite well with the HAZ. When the hatch distance is increased (reduced overlapping), the distance between the HAZ is also increased, which is the case for the FMZ as well. One theory is that the FMZ could essentially be the same as the HAZ. One piece of evidence to support this theory is that the width of the HAZ measured from single track sample (Fig. 5) is similar (the same order of magnitude) to the width of the FMZ. The width of the FMZ was moreover measured using several different overlappings, and it is roughly constant, as should be the case of HAZ when the process parameters are constant. In this work, the target laser spot size was $0.1 \mathrm{~mm}$, and alternating this process parameter was not conducted. However, increasing the spot size would undoubtedly increase the MZ and increase the overlapping between neighboring scan tracks. If the hatch distance remains constant, this would then decrease the BMP, as shown in Fig. 4. Modeling is not a part of this work, but if it would be possible to model the thermal history (with all the necessary process parameters taken into consideration), which should be different in the HAZ compared to the FMZ, that would either further support or disprove the theory that the HAZ is the same as the FMZ. It is, however,
Fig. 9 Overview of the 4 heat treatments. At $700^{\circ} \mathrm{C}$, see a, the $\mathrm{BMP}$ and microstructure are the same as in as-built condition, whereas a coarsening effect of the needles $\left(\alpha^{\prime} \rightarrow \alpha\right)$ is observed at 800 and $900{ }^{\circ} \mathrm{C}$, see $\mathbf{b}$ and $\mathbf{c}$ respectively. The BMP morphology still exists at 800 and $900^{\circ} \mathrm{C}$. However, for the $1020^{\circ} \mathrm{C}$ HT, the BMP disappears and instead of a martensitic a basket weave microstructure emerged

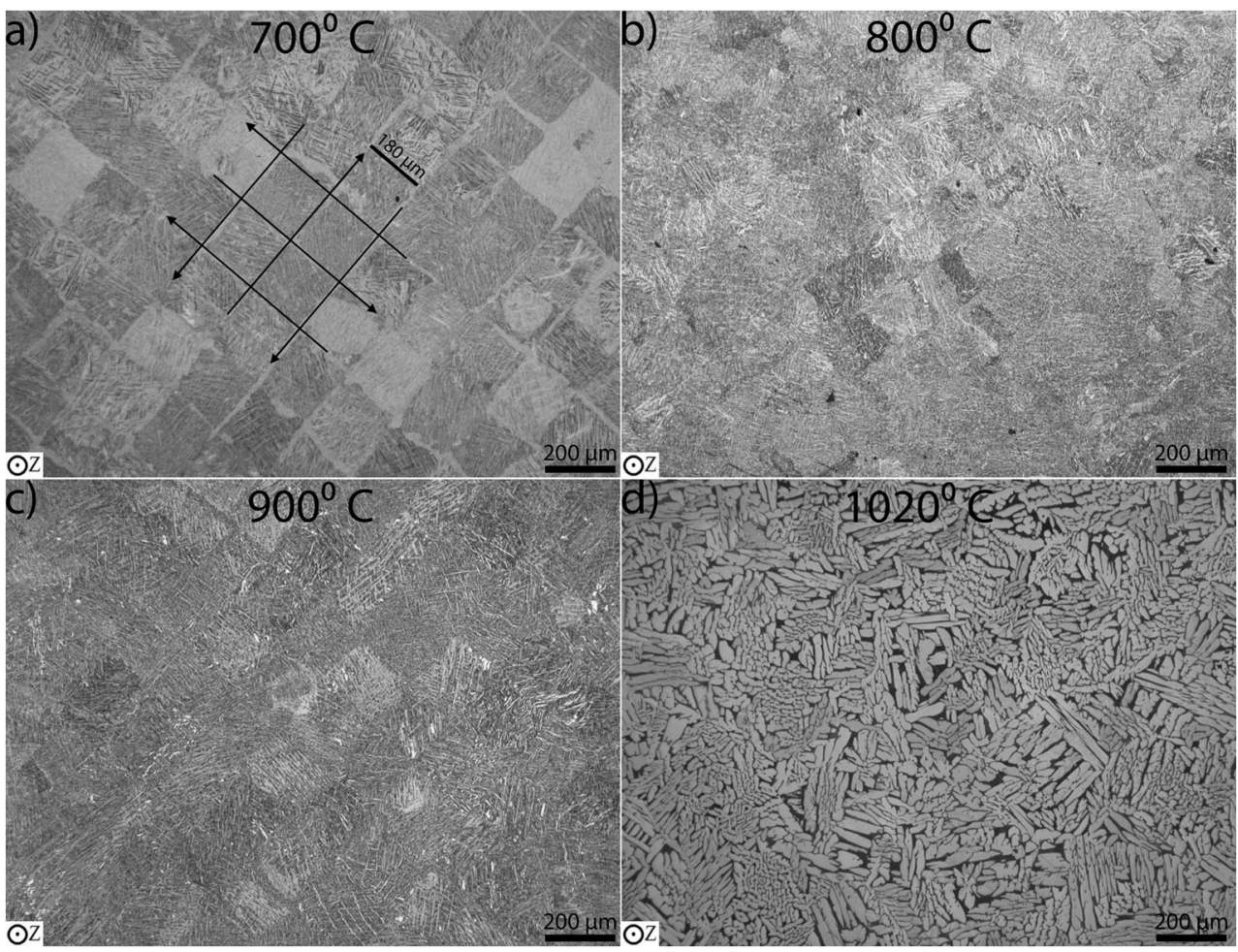




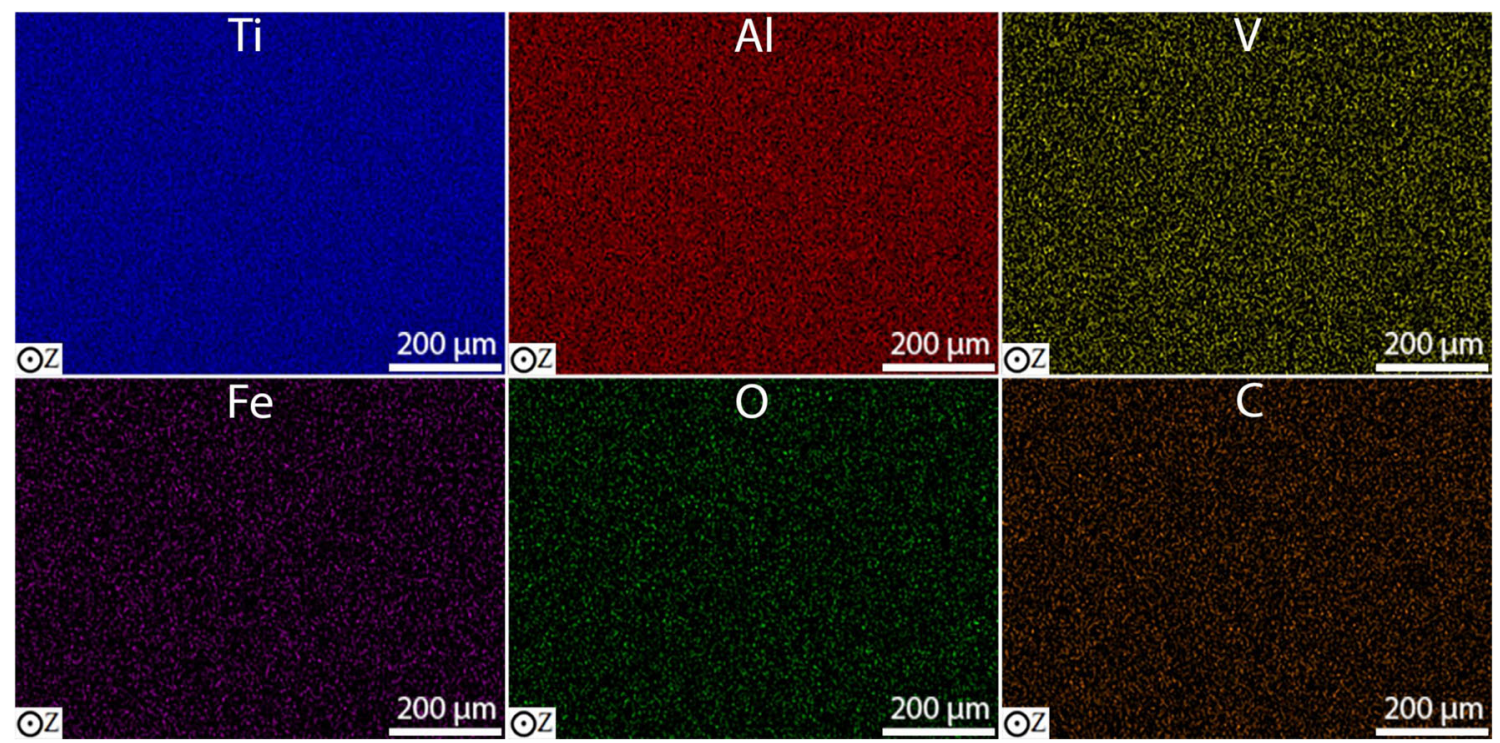

Fig. 10 The EDS mapping result. Ti, Al, and V were the main constituents and very small amounts of Fe, $\mathrm{O}$, and $\mathrm{C}$ were detected. No segregational trends could be identified

possible that the formation of the FMZ is caused by cyclic remelting of pre-solidified material. Previous work by, e.g., Kelly et al. [37] has shown that cyclic heating can cause microstructural changes in Ti-6Al-4V material. Modeling thermal history could shed some light on this theory as well.

SLM is known to have high thermal gradients, i.e., martensitic microstructure, and these high thermal gradients can lead to segregation phenomena. Thijs et al. [28] have shown that segregation of $\mathrm{Al}$ can occur in SLM built Ti-6Al-4V. It is known that differences in alloying elements can alter the microstructure [26], thus possibly explaining the microstructural difference in CMZ and FMZ. Therefore, EDS mapping was performed to investigate any possible segregational effect between the CMZ and FMZ. The results showed a homogenous distribution, thus indicating no presence of segregation in the material. It is, however, known that EDS has some accuracy issues [38]. In a recent study, Alistair et al. [39] used an electron probe micro- analyzer (EPMA), which is a chemical detection technique that is more precise than EDS, to detect micro segregation effects in the macrostructural parallel bands (a phenomenon that occurs for wire-based AM processes with fast cooling rates [37], where the microstructure is altered). The result was that a segregation layer was found in the boundary of each melt track, showing evidence of weak segregation during solidification. The segregation bands were attributed to a transient solute boundary layer at the solidification front. For the main alloying elements $\mathrm{Al}$ and $\mathrm{V}$, the effect was weak, and for $\mathrm{Fe}$ nonetheless it was significant (due to the lower partition coefficient of $\mathrm{Fe}$ ). The segregation of Fe reduced the $\beta$ stability, thus locally influencing the microstructure. The FMZ occurs in the boundary of each melt track as well, in accordance with these findings. Therefore, a future investigation would be to qualitatively investigate the BMP with EPMA, possibly finding chemical segregations that are not detectable with EDS.

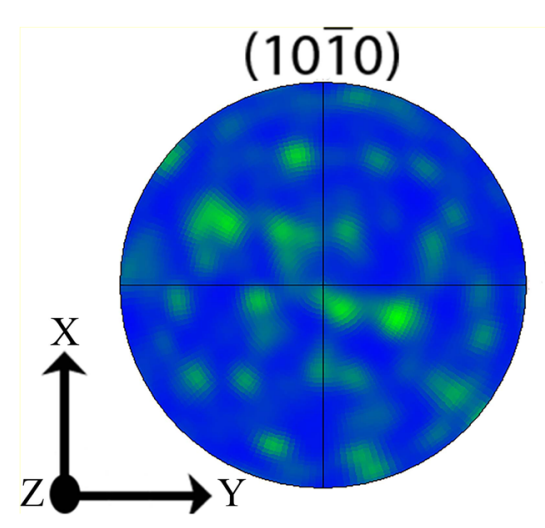

Fig. 11 Pole figures of the three HCP slip planes from the EBSD measurement shown in Fig. 8. To the right is the color code indicating the level of multiples of random distribution (MUD), i.e., red signifies the


strongest texture. The strongest texture lies in the X-Y plane of the (0002) plane, where $\mathrm{Z}$ is the build direction 
It was shown that the FMZ consists of individual prior $\beta$ grains, being separated from the $\mathrm{CMZ}$ prior $\beta$ grains. In Fig. $3 \mathrm{c}$, the microstructure is shown from a side view, i.e., perpendicular to the layers. The cooling rate to obtain martensitic microstructures is so fast that the nucleation of the $\alpha$ phase from the grain boundaries is suppressed, thus what is shown in Fig. $3 \mathrm{c}$ cannot be grain boundary $\alpha$. The thin columnar microstructural features with lighter contrast in Fig. $3 \mathrm{c}$ are thus determined to be the FMZ rather than grain boundary $\alpha$. Therefore, it could also be argued that the FMZ has a columnar morphology as well, separating the columnar prior $\beta$ grains that originates from the CMZ. Figure 7 shows a high-magnification IPF map and its corresponding reconstructed $\beta$ map. It shows that the FMZ has a different prior $\beta$ orientation compared to the CMZ. In Fig. 8, a side view of the reconstructed $\beta$ also shows that the larger $\beta$ grains are in most cases surrounded by thinner $\beta$ grains that have the same width as the FMZ. The fact that the FMZ and $\mathrm{CMZ}$ originate from separate parent $\beta$ grains confirmed by EBSD and $\beta$ reconstruction (Figs. 6, 7, and 8) suggests that the binary microstructure observed in light microscopy are prior $\beta$ grains of different shapes and widths (Fig. 3c).

It is possible that the BMP affects the mechanical properties because generally speaking different microstructures have different mechanical properties. The inhomogeneous microstructure could, for example, lead to crack initiation at the $\mathrm{CMZ}$ and FMZ interface, leading to premature failure. Or it could act as composite improving the properties. Linking the BMP to the mechanical properties, whether they are deteriorated, the same or improved, has not been the scope of this current, but could be additional future work. A possible way would be to expose SLM built material (with a BMP) to fatigue parallel the added layers. Thus, through statistical fractography, an attempt to correlate fracture surfaces to the microstructural features could be investigated. However, defects would, of course, make this investigation difficult. It is however likely the pattern affects the mechanical properties anisotropically as it has been observed to be present SLM built material [24, 40, 41]. Qiu et al. [24] attributed the anisotropy to the columnar structure of the prior $\beta$ grains and in this work has shown the BMP, in essence, are the prior $\beta$ grains. Although EBSD does not probe the whole sample volume, the results show the presence of texture that also would influence the mechanical properties anisotropically. This texture is related to the columnar structure of the prior $\beta$ grains. Given this anisotropic behavior, one should design SLM built components so that the intended load is applied in parallel to the layers (which is where the strength is highest [40, 42]).

\section{Conclusions}

To further understand the formation of the binary microstructure pattern in selective laser-melted Ti-6Al-4V, a thorough characterization was conducted, investigating the material with a light optical microscope, a scanning electron microscope and electron backscattered diffraction. The following conclusions are then drawn:

- By measuring the $\alpha^{\prime}$ needles' length and width, it shows that the fine microstructure zone has a finer microstructure than the corresponding coarse microstructure zone. In addition, the aspect ratio of martensite in the fine microstructure zone is lower than that in the coarse microstructure zone.

- The size of the binary microstructure pattern depends on the overlapping, i.e., hatch spacing, a decreased overlapping (an increased hatch distance) renders an increased size of the coarse microstructure zone. However, no such trend was in evidence for the fine microstructure zone, where the width of the fine microstructure zone remained constant at different overlapping values.

- The binary microstructure pattern remained after sub $\beta$ transus temperature heat treatments while disappearing above super $\beta$ transus temperature.

- The coarse and fine microstructure zones have different prior $\beta$ grain orientations according to $\beta$ grain reconstructions.

Acknowledgments The author would like to thank Monash Centre for Additive Manufacturing (MCAM) for making it possible to perform this research. For proof reading assistance, the author would like to thank Dr. Richard Kelly. Finally, the author would like to thank Dr. Zhuoer Chen, Dr. Sheng Cao, and Dr. Kai Zhang for their valuable contributions.

Funding information The author received financial support from the "Nationellt rymdtekniskt forsknings program" (NRFP), the EU funded project "Space for innovation and growth" (RIT), and the "Graduate School of Space Technology" at Luleå University of Technology and "Hans Werthén Fonden."

Open Access This article is distributed under the terms of the Creative Commons Attribution 4.0 International License (http:// creativecommons.org/licenses/by/4.0/), which permits unrestricted use, distribution, and reproduction in any medium, provided you give appropriate credit to the original author(s) and the source, provide a link to the Creative Commons license, and indicate if changes were made.

\section{References}

1. Vrancken B, Thijs L, Kruth J, Van Humbeeck J (2012) Heat treatment of Ti6Al4V produced by selective laser melting: microstructure and mechanical properties. J Alloys Compd 541:177-185

2. Xu W, Lui EW, Pateras A, Qian M, Brandt M (2017) In situ tailoring microstructure in additively manufactured Ti-6Al-4V for superior mechanical performance. Acta Mater 125:390-400

3. Cao S, Chen Z, Lim CVS, Yang K, Jia Q, Jarvis T, Tomus D, Wu X (2017) Defect, microstructure, and mechanical property of Ti-6Al$4 \mathrm{~V}$ alloy fabricated by high-power selective laser melting. JOM 69(12):2684-2692 
4. Neikter M, Åkerfeldt P, Pederson R, Antti M, Sandell V (2018) Microstructural characterization and comparison of Ti-6Al-4V manufactured with different additive manufacturing processes. Mater Charact 143:68-75

5. Neikter M (2017) Microstructure and texture of additive manufactured Ti-6Al-4V. Luleå University of Technology, Luleå

6. Frazier WE (2014) Metal additive manufacturing: a review. J Mater Eng Perform 23(6):1917-1928

7. Lewandowski JJ, Seifi M (2016) Metal additive manufacturing: a review of mechanical properties. Annu Rev Mater Res 46:151-186

8. Xu W, Brandt M, Sun S, Elambasseril J, Liu Q, Latham K, Xia K, Qian M (2015) Additive manufacturing of strong and ductile Ti$6 \mathrm{Al}-4 \mathrm{~V}$ by selective laser melting via in situ martensite decomposition. Acta Mater 85:74-84

9. Faubert FM, Springer GS (1972) Measurement of the thermal conductivity of argon, krypton, and nitrogen in the range $800-2000^{\circ} \mathrm{K}$. J Chem Phys 57(6):2333-2340

10. Yang J, Yu H, Wang Z, Zeng X (2017) Effect of crystallographic orientation on mechanical anisotropy of selective laser melted Ti6Al-4V alloy. Mater Charact 127:137-145

11. Muhammad M, Pegues JW, Shamsaei N, Haghshenas M (2019) Effect of heat treatments on microstructure/small-scale properties of additive manufactured Ti-6Al-4V. Int J Adv Manuf Technol 112. https://doi.org/10.1007/s00170-019-03789-w

12. Yang J, Yu H, Yin J, Gao M, Wang Z, Zeng X (2016) Formation and control of martensite in Ti-6Al-4V alloy produced by selective laser melting. Mater Des 108:308-318

13. He B, Wu W, Zhang L, Lu L, Yang Q, Long Q, Chang K (2018) Microstructural characteristic and mechanical property of Ti6A14V alloy fabricated by selective laser melting. Vacuum 150:79-83

14. Magnus Neikter P, Åkerfeldt R (2017) Pederson and Marta-Lena Antti. Microstructure characterisation of Ti-6Al-4V from different additive manufacturing processes. IOP Conference Series: Materials Science and Engineering: IOP Publishing

15. Mercelis P, Kruth J (2006) Residual stresses in selective laser sintering and selective laser melting. Rapid Prototyp J 12(5):254-265

16. Neikter M, Woracek R, Maimaitiyili T, Scheffzük C, Strobl M, Antti $\mathrm{M}$ et al (2018) Alpha texture variations in additive manufactured Ti-6Al-4V investigated with neutron diffraction. Addit Manuf 23:225-234

17. Cao S, Chu R, Zhou X, Yang K, Jia Q, Lim CVS, Huang A, Wu X (2018) Role of martensite decomposition in tensile properties of selective laser melted Ti-6Al-4V. J Alloys Compd 744:357-363

18. Maimaitiyili T, Woracek R, Neikter M, Boin M, Wimpory RC, Pederson R et al (2019) Residual lattice strain and phase distribution in Ti-6Al-4V produced by electron beam melting. Materials 12(4):667

19. Mugwagwa L, Dimitrov D, Matope S, Yadroitsev I (2019) Evaluation of the impact of scanning strategies on residual stresses in selective laser melting. Int J Adv Manuf Technol 102(5-8): 2441-2450

20. Ali H, Ghadbeigi H, Mumtaz K (2018) Effect of scanning strategies on residual stress and mechanical properties of selective laser melted Ti6A14V. Mater Sci Eng A 712:175-187

21. AlMangour B, Grzesiak D, Yang J (2017) Scanning strategies for texture and anisotropy tailoring during selective laser melting of $\mathrm{TiC} / 316 \mathrm{~L}$ stainless steel nanocomposites. J Alloys Compd 728: 424-435

22. Koutny D, Palousek D, Pantelejev L, Hoeller C, Pichler R, Tesicky L, Kaiser J (2018) Influence of scanning strategies on processing of aluminum alloy EN AW 2618 using selective laser melting. Materials 11(2):298

23. Pal S, Lojen G, Kokol V, Drstvensek I (2018) Evolution of metallurgical properties of Ti-6Al-4V alloy fabricated in different energy densities in the selective laser melting technique. J Manuf Process 35:538-546
24. Qiu C, Adkins NJE, Attallah MM (2013) Microstructure and tensile properties of selectively laser-melted and of HIPed laser-melted Ti6Al-4V. Mater Sci Eng A 578:230-239

25. Simonelli M, Tse YY, Tuck C (2014) Effect of the build orientation on the mechanical properties and fracture modes of SLM Ti-6Al4V. Mater Sci Eng A 616:1-11

26. Lütjering G, Williams JC (2007) Titanium. 2nd edn, Springer, Berlin Heidelberg

27. Neikter M, Forsberg F, Pederson R, Antti M, Åkerfeldt P, Larsson S et al (2018) Defect characterization of electron beam melted Ti-6Al4V and alloy 718 with X-ray microtomography. Aeronaut and Aeros Open Acc J 2(3):139-145

28. Thijs L, Verhaeghe F, Craeghs T, Van Humbeeck J, Kruth J (2010) A study of the microstructural evolution during selective laser melting of Ti-6Al-4V. Acta Mater 58(9):3303-3312

29. Saeidi K, Neikter M, Olsen J, Shen ZJ, Akhtar F (2017) 316L stainless steel designed to withstand intermediate temperature. Mater Des 135:1-8

30. Carter LN, Martin C, Withers PJ, Attallah MM (2014) The influence of the laser scan strategy on grain structure and cracking behaviour in SLM powder-bed fabricated nickel superalloy. J Alloys Compd 615:338-347

31. Cayron C (2007) ARPGE: a computer program to automatically reconstruct the parent grains from electron backscatter diffraction data. J Appl Crystallogr 40(6):1183-1188

32. Humbert M, Wagner F, Esling C (1992) Numbering the crystallographic variants in phase transformation. J Appl Crystallogr 25(6): 724-730

33. Cayron C (2006) Groupoid of orientational variants. Acta Crystallogr A 62:21-40

34. Zhang X, Fang G, Leeflang S, Böttger AJ, Zadpoor AA, Zhou J (2018) Effect of subtransus heat treatment on the microstructure and mechanical properties of additively manufactured Ti-6Al-4V alloy. J Alloys Compd 735:1562-1575

35. Bormann T, Müller B, Schinhammer M, Kessler A, Thalmann P, de Wild M (2014) Microstructure of selective laser melted nickel-titanium. Mater Charact 94:189-202

36. Yadroitsev I, Yadroitsava I, Bertrand P, Smurov I (2012) Factor analysis of selective laser melting process parameters and geometrical characteristics of synthesized single tracks. Rapid Prototyp J 18(3):201-208

37. Kelly SM, Kampe SL (2004) Microstructural evolution in laserdeposited multilayer Ti-6Al-4V builds: part I. microstructural characterization. Metall Mater Trans A 35(6):1861-1867

38. Goldstein JI (2003) Scanning electron microscopy and x-ray microanalysis. 3rd edn, Springer, New York

39. Ho A, Zhao H, Fellowes JW, Martina F, Davis AE, Prangnell PB (2019) On the origin of microstructural banding in Ti-6A14V wirearc based high deposition rate additive manufacturing. Acta Mater 166:306-323

40. Rafi HK, Karthik NV, Gong H, Starr TL, Stucker BE (2013) Microstructures and mechanical properties of Ti6Al4V parts fabricated by selective laser melting and electron beam melting. J Mater Eng Perform 22(12):3872-3883

41. Chen LY, Huang JC, Lin CH, Pan CT, Chen SY, Yang TL, Lin DY, Lin HK, Jang JSC (2017) Anisotropic response of Ti-6Al-4V alloy fabricated by $3 \mathrm{D}$ printing selective laser melting. Mater Sci Eng A 682:389-395

42. Cain V, Thijs L, Van Humbeeck J, Van Hooreweder B, Knutsen R (2015) Crack propagation and fracture toughness of Ti6A14V alloy produced by selective laser melting. Addit Manuf 5:68-76

Publisher's note Springer Nature remains neutral with regard to jurisdictional claims in published maps and institutional affiliations. 